\title{
Welfare assessment of two hybrids of laying hens housed in conventional cages
}

\author{
H.D.H. Mahboub ${ }^{1}$, I.M. Fares ${ }^{2}$, R.A. Darwish ${ }^{3}$ \\ ${ }^{1}$ Department of Husbandry and Animal Wealth Development, Faculty of Vet. Med., Sadat City \\ Branch, Menoufia University, ${ }^{2}$ Department of Hygiene, Zoonoses and Animal Behaviour and \\ Management, Faculty of Vet. Med., Suez Canal University and ${ }^{3}$ Department of Animal Husbandry, \\ Faculty of Vet. Med., Mansoura University, Egypt.
}

\begin{abstract}
The aims of this study were twofold: to assess the welfare of two hybrids of laying hens in conventional cages and to investigate the effects of tier's level on the integument condition and fearfulness. Two commercial hybrids, white Lohmann Selected Leghorn (LSL) and brown Lohmann Traditional (LT) at about 18 weeks of age were used in the current study and were housed at three hens / cage. No birds were beak-trimmed. External appearance of the body (scoring of plumage condition and skin injuries at body parts and comb), heterophil-lymphocyte (H-L) ratios and duration of tonic immobility (TI) were used as indicators of well-being. LSL birds showed better plumage condition and low H-L ratios than LT birds while no significant difference was recorded in TI test between the two hybrids. Hens housed in the top tier showed worse feather condition and more wounds than birds in middle and bottom tiers whereas for fear levels, no significant difference was revealed for hens from different tiers of cages. These results suggest that the welfare of LSL birds was relatively good compared to LT. Therefore, conventional cages can be used by the hens to a large extent if birds are properly selected to be specifically adapted to cages.
\end{abstract}

In Egypt, cage systems form about $30.4 \%$ of the laying hen farms and produce about $81.1 \%$ of the table eggs per year (APWDS, 2004). Cages for laying hens are efficient in terms of feed usage, ease of management and they provide clean, good quality (food safe) eggs for the consumer. On the other hand, conventional cages are less likely than other husbandry systems to provide freedom of movement, freedom from fear, comfort, shelter, suitable floor space and freedom to perform natural behaviours. The restriction or even absence of certain behaviour patterns, such as dust bathing (Vestergaard, 1982), foraging behaviour (scratching and pecking) (Blokhuis, 1989), comfort behaviour (wing flapping, body shaking and stretching) (Nicol, 1987) and pre-laying behaviour (Wood-Gush, 1972), might cause severe frustration and stress and/or develop abnormal behaviours leading to drop in production and reproduction as well as poor welfare.

Damaging feather pecking is a major welfare problem in laying hens and turkeys, particularly when it leads to cannibalism and the painful death of target birds. Therefore, deterioration of plumage and reduction of body coat impair the performance and welfare of laying hen by affecting thermoregulation, incidence of injury and behaviour (McAdie and Keeling, 2000). Feather condition is generally worse in cages than in non-cage systems (McLean et al., 1986; Appleby et al., 1988). Feather loss from abrasion is usually worse in cage, but the main reason for loss in all systems is feather pecking (Hughes, 1985).

Examining the condition of integument is applied as an indirect method for evaluation of feather pecking activity in the flock (Bilcik and Keeling, 1999). Huber-Eicher and Sebö, (2001) found that increased frequency of feather pecking is associated with more feather damage. Some scoring methods give a single subjective score for the entire body (Adams et al., 1978) while others scoring different body parts individually and summing scores afterwards (Eissele-Kraft, 1993; Tauson et al., 1984).

Nowadays fear is widely regarded as an undesirable state of suffering in animals and poultry. High levels of underlying fearfulness have been negatively associated with egg production (Barnett et al., 1992), egg shell 
quality (Jones and Hughes, 1986), growth (Bessei, 1984), and food conversion efficiency (Hemsworth et al., 1994). Furthermore, there is a positive relationship between fear and feather damage and/or feather pecking (Craig et al., 1983; Okpokho et al., 1987). Indeed, fear level of caged birds varies between different tiers of a battery where birds from the top tier showed more fearfulness than birds from other tiers. This high level of fear may have been responsible for the lower productivity of the birds that housed in top tiers (Hemsworth and Barnett, 1989). The injuries caused directly or indirectly by the elicitation of acute fear states represent a major welfare problem because they can lead to chronic pain, infection, physical debilitation and undesirable behaviours. The tonic immobility (TI) is a useful index of fearfulness in fowl. The TI duration is thought to be positively related to underlying fearfulness (Gallup, 1979; Jones, 1986; 1996).

The other indices of welfare assessment include physiological index of stress. The heterophil-lymphocyte (H-L) ratio has been considered as a reliable and accurate physiological index of the stress in chickens (Gross and Siegel, 1983; Maxwell, 1993). The avian heterophil is considered as a window to the health state of bird (Lane, 1987) and will respond to problems associated with diet, chronic bacterial infections, stress, light and trauma (Jones, 1989; Hocking et al., 1999; Campo and Davila, 2002).

The goals of this study were to assess the welfare of two hybrids of laying hens in conventional cages on the basis of feather damage, tonic immobility and heterophillymphocyte ratio and to investigate the effects of tier's level on the integument condition and fearfulness.

\section{Materials and methods}

Birds and husbandry. The study included 150 brown Lohmann Traditional (LT) and 120 white Lohmann Selected Leghorn (LSL) laying hens. They were reared together on the floor and were not beak-trimmed. At 18 weeks of age, the birds were marked with metal leg rings and transferred to the experimental room, where they housed in conventional three-tiers cages ( 3 hens per cage, $\mathrm{n}=30$ for both strain) at stocking density $550 \mathrm{~cm}^{2}$ /bird (cage $35 \times 50 \times 40 \mathrm{~cm}$ ). The hens fed and watered ad libitum daily and observed for 10 days of acclimatization before data collection commenced. Eggs were collected every other day by hand. The light regimen in the house was
$14 \mathrm{~h}$ light: $10 \mathrm{~h}$ dark and temperature was kept between $20-25^{\circ} \mathrm{C}$.

\section{Measurements.}

External appearance of the body. Scoring of external appearance of the body feather was carried out at 30, 34, 38, 42 and 46 weeks of age. All hens were individually assessed for feather damage, feather loss and skin lesions. The body of the bird was divided into 5 parts: 1) cranial part (head and upper neck), 2) dorsal part (back and rump), 3) caudal part (tail and belly), 4) lateral part (wing-primaries, wing-coverts and leg) and 5) ventral part (under neck and breast). The scoring system assigned values of 0 (no damage) to 6 (severe damage) points for condition of plumage (Mahboub, 2004) and wounds on the comb and all parts of the body were scored from 0 (no lesion) to 4 (large wound) (Bilcik and Keeling, 1999). The variables of plumage condition for body parts were summarised; implying a total body score ranging from 0 (no damaged feathers) to 66 (all feathers damaged or lost) points.

Physiological measurements (heterophillymphocyte ratios). On two consecutive days at 44 weeks of age, all the hens were caught and blood samples were collected (Mahboub et al., 2004). One drop of blood from each individual was obtained by venepuncture of a wing vein, placed on duplicate glass microscope slide, and then smeared with the canted edge of a second slide. After drying, the slides were stained using Wright's stain (Shen and Patterson, 1983). One hundred Leucocytes per slide, including heterophils, eosinophils, basophils lymphocytes and monocytes were counted at 1,000x (oil immersion lens) and heterophil-lymphocyte (HL) ratios calculated.

Behavioural measurements (Tonic immobility test). Tonic immobility (TI) was measured in each bird at 44 weeks of age (Mahboub et al., 2004). Testing took place on 2 consecutive days from 08:00 to 14:00 h. TI was induced by restraining the bird on its back for $15 \mathrm{~s}$ in a Vshaped metal cradle covered with several layers of clothing, with the head hanging outside as described by Jones and Faure (1981). The operator held one hand over the bird sternum and after removing his hand, a stopwatch was started while the experimenter retreated about 1.5 to $2 \mathrm{~m}$ away of the sight of the bird. The duration of TI, latency to self-righting, was recorded. The bird was considered as being in a state of TI if it remained immobile for a minimum of $10 \mathrm{~s}$ after removing the operator's hand. The maximum 
duration of TI was set to $1200 \mathrm{~s}$. If the bird righted itself in less than $10 \mathrm{~s}$, the procedure was repeated again. If TI was not induced after three attempts, the bird was given a zero score.

Live body weight. To study the live body weight for both strains, all the hens were weighed at 34 and 42 weeks of age.

Statistical analysis. Statistical analyses were performed by using the SAS system (SAS Institute Inc., 1999). The data obtained from feather score, TI, leukocyte numbers, H-L ratios and body weight were subjected to analysis of variance technique (ANOVA using PROC GLM).

\section{Results}

The external appearance of the body was affected by hybrid and tier of the cage. (Table 1) revealed that LSL hens had generally better plumage condition than LT hens $(P<0.001)$. Feathers of lateral part, including wings (primaries and coverts) and legs, were worse when compared with other body parts in both strains. At all ages, LT hens showed more feather damage and loss than LSL (Fig.1). In addition, feather scores in both strains increased with age during the production period as shown in (Fig.1). Although, there were no striking differences between genotypes for the probability of skin injuries on all parts of the body, LSL hen's combs had a significantly $(P<0.05)$ more scratches than comb of LT hens (Table 2).

Total feather score was significantly higher in laying hens housed in top tiers than those in middle and bottom tiers in both LSL $(P<0.01)$ and LT $(P<0.05)$ hens as shown in (Table3). In addition, LT hens had more feather damage in both middle $(P<0.001)$ and bottom $(P<0.01)$ tiers than LSL hens. At the same time, feather condition in top-tier birds was similar in both strains $(P=0.098)$ (Table 3$)$. The scoring of external appearance revealed that more wounds were recorded on the body parts $(P<0.001)$ and combs $(P<0.01)$ in LSL hens that housed in top tiers compared to birds in both middle and bottom tiers as given in (Table 4). There were no significant differences in skin injuries either on the body parts or on combs between tiers for LT hens.

LS-means $( \pm$ SE $)$ of TI, H-L ratios and proportions (\%) of white blood cells are presented in (Table 5). No significant $(P=0.898)$ differences were found in TI reaction between LSL and LT hens. Moreover, there was no effect of tier level on the duration of TI. Short TI duration was found in LSL hens housed in the middle tier compared to top and bottom tiers but the differences were not significant (LS-means \pm SE respectively were $368.2 \pm 138.1$ versus 565.0 \pm 206.7, 515.6 $\pm 177.2, P=0.332)$. The H-L ratios and proportions of lymphocytes and heterophils were significantly higher in the LT hens than LSL hens $(P<0.001)$.

Body weight was affected by genotypes whereas LT hens had a significant high body weight compared to LSL hens (mean $\pm \mathrm{SE}$, $2014.0 \pm 31.2$ vs. $1741.1 \pm 29.0$ gm respectively, $P<0.001)$.

Table (1): Plumage condition ${ }^{1}$ (LS-means \pm SE) as affected by genotype (LSL and LT).

\begin{tabular}{lccc}
\hline \multirow{2}{*}{ Body parts } & \multicolumn{2}{c}{ Hybrids } & \multirow{2}{*}{$\boldsymbol{P}$-value } \\
\cline { 2 - 3 } & LSL & LT & $*$ \\
Cranial & $5.20 \pm 0.26$ & $6.34 \pm 0.14$ & $* * *$ \\
Dorsal & $4.24 \pm 0.16$ & $6.25 \pm 0.11$ & $* *$ \\
Caudal & $6.59 \pm 0.22$ & $7.46 \pm 0.10$ & $* *$ \\
Lateral & $7.21 \pm 0.20$ & $8.78 \pm 0.14$ & $* *$ \\
Ventral & $6.06 \pm 0.20$ & $7.94 \pm 0.09$ & $* * *$ \\
Total & $29.30 \pm 0.88$ & $36.76 \pm 0.48$ & \\
\hline
\end{tabular}

${ }^{1}$ The lower scores indicate better plumage. $* P<0.05, * * P<0.01, * * * P<0.001$. 
Table (2): Skin injuries ${ }^{1}$ in different body parts and comb (LS-means \pm SE) as affected by genotype (LSL and LT).

\begin{tabular}{lccc}
\hline \multirow{2}{*}{ Body parts } & \multicolumn{2}{c}{ Hybrids } & \multirow{2}{*}{$\boldsymbol{P}$-value } \\
\cline { 2 - 3 } & LSL & LT & $\mathrm{ns}$ \\
Cranial & $0.00 \pm 0.00$ & $0.03 \pm 0.02$ & $\mathrm{~ns}$ \\
Dorsal & $0.23 \pm 0.08$ & $0.15 \pm 0.04$ & $\mathrm{~ns}$ \\
Caudal & $0.34 \pm 0.12$ & $0.26 \pm 0.05$ & $\mathrm{~ns}$ \\
Lateral & $0.08 \pm 0.04$ & $0.09 \pm 0.02$ & $\mathrm{~ns}$ \\
Ventral & $0.14 \pm 0.08$ & $0.12 \pm 0.04$ & $\mathrm{~ns}$ \\
Total & $0.78 \pm 0.21$ & $0.64 \pm 0.09$ & $*$ \\
Comb & $0.89 \pm 0.08$ & $0.47 \pm 0.04$ & \\
\hline
\end{tabular}

${ }^{1}$ The higher scores indicate more skin injuries. $* P<0.05$. ns: non-significant.

Table (3): Plumage condition (LS-means \pm SE) as affected by tiers and genotype (LSL and LT hens).

\begin{tabular}{lccc}
\hline \multirow{2}{*}{ Tier } & \multicolumn{2}{c}{ Hybrids } & \multirow{2}{*}{$\boldsymbol{P}$-value } \\
\cline { 2 - 4 } & LSL & LT & $\mathrm{ns}$ \\
Top & $36.68 \pm 1.71^{\mathrm{a}}$ & $39.12 \pm 0.58^{\mathrm{a}}$ & $* * *$ \\
Middle & $24.50 \pm 0.80^{\mathrm{b}}$ & $35.57 \pm 0.86^{\mathrm{b}}$ & $* *$ \\
Bottom & $26.77 \pm 0.81^{\mathrm{b}}$ & $35.86 \pm 0.91^{\mathrm{b}}$ & \\
$\boldsymbol{P}$-value & $* *$ & $*$ & \\
\hline
\end{tabular}

a-b litters have shown significant differences within column.

${ }^{*} P<0.05,{ }^{* *} P<0.01,{ }^{* * *} P<0.001$. ns: non-significant.

Table (4): Skin injuries (LS-means \pm SE) as affected by tiers and genotype (LSL and LT hens).

\begin{tabular}{llcccc}
\hline & \multirow{2}{*}{ Hybrids } & \multicolumn{3}{c}{ Tier } & \multirow{2}{*}{ P-value } \\
\cline { 3 - 5 } & & Top & Middle & Bottom & \\
\hline Skin & LSL & $1.72 \pm 0.61^{\mathrm{a}}$ & $0.25 \pm 0.14^{\mathrm{b}}$ & $0.40 \pm 0.15^{\mathrm{b}}$ & $* * *$ \\
injuries $^{1}$ & LT & $0.73 \pm 0.15$ & $0.48 \pm 0.13$ & $0.77 \pm 0.18$ & $\mathrm{~ns}$ \\
\multirow{2}{*}{ Comb } & LSL & $1.28 \pm 0.16^{\mathrm{a}}$ & $0.50 \pm 0.14^{\mathrm{b}}$ & $0.83 \pm 0.11^{\mathrm{b}}$ & $* *$ \\
& LT & $0.44 \pm 0.09$ & $0.44 \pm 0.06$ & $0.54 \pm 0.09$ & $\mathrm{~ns}$ \\
\hline
\end{tabular}

${ }^{1}$ Total skin injuries scores for all body parts.

a-b litters have shown significant differences between column.

** $P<0.01, * * * P<0.001$. ns: non-significant.

Table (5): Tonic immobility (TI), H-L ratio and proportions (\%) of white blood cells (LS-means $\pm \mathrm{SE}$ ) as affected by genotype (LSL and LT hens).

\begin{tabular}{lccc}
\hline \multirow{2}{*}{ Variables } & \multicolumn{2}{c}{ Hybrids } & \multirow{2}{*}{$\boldsymbol{P}$-value } \\
\cline { 2 - 3 } & LSL & LT & $\mathrm{ns}$ \\
\hline TI (s) & $477.56 \pm 127.44$ & $511.08 \pm 76.47$ & $* * *$ \\
H/L ratio & $0.31 \pm 0.03$ & $0.63 \pm 0.06$ & $* * *$ \\
Lymphocytes & $67.83 \pm 1.72$ & $55.94 \pm 2.35$ & $\mathrm{~ns}$ \\
Monocytes & $8.78 \pm 0.91$ & $7.63 \pm 0.79$ & $\mathrm{~ns}$ \\
Basophils & $1.65 \pm 0.25$ & $1.81 \pm 0.28$ & $\mathrm{~ns}$ \\
Esinophils & $1.34 \pm 0.21$ & $1.31 \pm 0.35$ & $* * *$ \\
Heterophils & $20.39 \pm 1.45$ & $33.31 \pm 2.02$ & \\
\hline
\end{tabular}

* $P<0.05,{ }^{* *} P<0.01,{ }^{* * *} P<0.001$. ns: non-significant. 
Fig. 1. Total feather scores for LSL and LT laying hens at different ages. $(* * P<0.01, * * * P<$ 0.001)

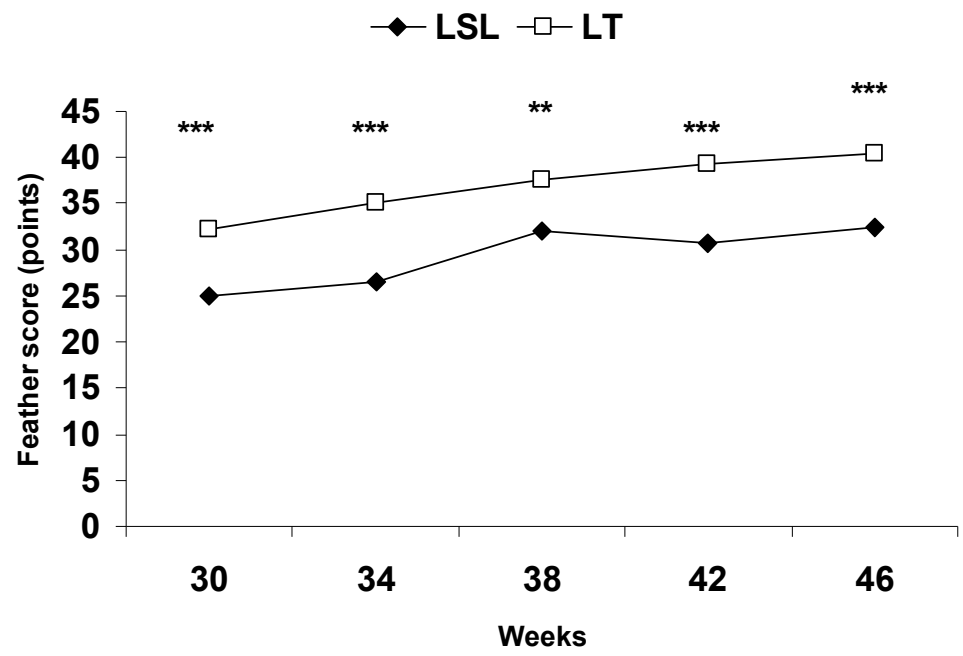

Discussion

Generally, strain differences considered important only if a significant difference detected. Whereas LSL hens had a lower body weight, better plumage condition and lower $\mathrm{H}-\mathrm{L}$ ratios than LT hens. LSL is a light-hybrid and the difference in live body weight between LSL and LT hens was therefore expected. Less feather damage that was recorded in LSL hens (score: 29.30) may be attributed to little feather pecking (Bilcik and Keeling, 1999; Huber-Eicher and Sebö, 2001) and to less contact with cage wall as a result their small and apparently slim body. On the contrary, more frequency of feather pecking activity and more contact with cage mesh due to heavy and apparently broad body may explain the worse plumage condition (score: 36.76) that observed in the LT birds. Indeed, it is obvious that cage walls have detrimental effect on lateral part that showed more feather loss and damage than other body parts (Hughes, 1985; Appleby and Hughes, 1991). Moreover, damaged feathers may lead to more plumage damage because they act as attractive target for feather pecking behaviour (McAdie and Keeling, 2000).

As the hens aged, they showed increasingly damage of feathers. These findings support the previous results (Mahboub, 2004) that reported increasing in feather scores with age during the laying period.

Comb injuries were generally more in LSL than LT hens even if they housed in cage or on floor (Mahboub, 2004). The possible explanation might be the comb size that was larger in LSL hens than LT. Therefore, the large comb size either stimulates more attacks or increases vulnerability to injuries by any attack (Cloutier and Newberry, 2002). Consequently, there was probably strong effect of genotype on comb injuries. Wounds (size: $<1 \mathrm{~cm}$ diameter) on the body as well as on the comb of LSL birds that housed in top tiers were more than other tiers. Therefore, the incidence of cannibalism in the top tiers may be higher. Hence, more attention may be necessary for birds in top tiers especially for LSL hens.

Corticosterone, supplied by infusion (Jones et al., 1988) or through the diet (El-lethey et al., 2001) causes raised H-L ratios and prolonged duration of TI, indicating that TI as well as H-L is closely related to stress. Consequently, LT hens that had high H-L ratios and numerically long TI reaction were more stressed than LSL hens. This stress condition is considered as a factor that may enhance the development of abnormal behaviour especially feather pecking (El-lethey et al., 2000). Based on TI, our result is in agreement with Scott et al., (1998) found no significant difference in the fear levels for hens from different tiers of cages. On the contrary, it does not agree with the previous studies that reported long durations of TI for birds housed in top tier (Jones, 1985); Barnett and Hemsworth (1989) found that birds in Top tiers, which had less human contact than birds from other tiers, were more fearfulness. This difference is likely to depend on husbandry techniques.

Furthermore, top tiers, which are the nearest to light source than other tiers, expose to high 
light intensity that stimulates more severe feather pecking (Kjaer and Vestergaard, 1999). Consequently, this may explain why birds housed in the top tier had more deteriorated plumage condition and wounds either on the body or on comb than did their middle- and bottom-tier counterparts.

In conclusion, there was indication that LSL hens were more accustomed to conventional cage than LT hens. On the basis of better plumage condition, low fearfulness and stress, it is suggested that the welfare of LSL birds was relatively good. Whereas, the welfare of birds that housed in top tiers was poor. Consequently, conventional cages can be used by the hens to a large extent if birds are properly selected to be specifically adapted to cages and if the house is improved especially source of light.

\section{References}

Adams, A. W.; Craig, J. V. and Bhagwat, A. L. (1978): Effects of flock size, age at housing, and mating experience on two strains of egg-type chickens in colony cages. Poult Scie., 57: 48-53.

Appleby, M. C.; Hogarth, G. S.; Anderson, J. A. Hughes, B.O. and Whittemore, C.T. (1988): Performance of a deep litter system for egg production. Br. Poult. Sci., 29: 735-751.

Appleby, M.C. and Hughes, B.O. (1991): Welfare of laying hens in cages and alternative systems: environmental, physical and behavioural aspects. World's Poult. Sci. J., 47: 109-128.

APWDS (Animal and Poultry Wealth Development Sector) (2004): Animal and Poultry Wealth Statistics 2003, Egyptian Ministry of Agriculture, 9: 71-72.

Barnett, J. L. and Hemsworth, P. H. (1989): Fear of humans laying hens in different tiers of a battery: behavioural and physiological responses. Br. Poult. Sci., 30: 497-504.

Barnett, J. L.; Hemsworth, P. H. and Newman, E.A. (1992): Fear of humans and its relationships with productivity in laying hens at commercial farms. Br. Poult. Sci., 33: 699-710.

Bessei, W. (1984): Genetische Beziehungen zwischen Leistung, Befiederung und Scheu bei Legehennen. Archiv f. Geflügelkunde 48: 231-239.

Bilcik, B. and Keeling, L. J. (1999): Changes in feather condition in relation to feather pecking and aggressive behaviour in laying hens. Br. Poult. Sci., 40: 444-451.

Blokhuis, H. J. (1989): The effect of a sudden change in floor type on pecking behaviour in chicks. App. Anim. Behav. Sci., 22: 65-73.

Campo, J.L. and Davila, S.G. (2002): Effect of photoperiod on heterophil to lymphocyte ratio and tonic immobility duration of chickens. Poult. Sci., 81: 1637-1639. Cloutier, S. and Newberry, R.C. (2002): Differences in skeletal and ornamental traits between laying hens cannibals, victims and bystanders. App. Anim. Behav. Sci., 77:115-126.

Craig,J. V.; Craig, T. P. and Dayton, A. D. (1983): Fearful behaviour by hens of two genetic stocks. App. Anim. Ethol., 10: 263-273

Eissele-Kraft, K. (1993): Einfluss des Schnabelkurzens auf das Verhalten, den Befiederungszustand und die Leistung von Legehennen. Dissertation, Universität Hohenheim, Verlag Ulrich E. Grauer, Wendlingen.

El-lethey, H.; Aerni, V.; Jungi, T.W. and Wechsler, B. (2000): Stree and feather pecking in laying hens in relation to housing condition. Br. Poult. Sci., 41: 22-28.

El-lethey, H.; Jungi, T.W. and Huber, E. (2001): Effects of feeding corticosterone and housing conditions on feather pecking in laying hens. Physiol. Behav., 73: 243-251.

Gallup, G.G. Jr. (1979): Tonic immobility as a measure of fear in domestic fowl. Anim. Behav., 20: 166-169.

Gross, W.B. and Siegel, H.S. (1983): Evaluation of the heterophil/lymphocyte ratio as a measure of stress in chickens. Avian Dis., 27: 972-979 .

Hemsworth, P.H. and Barnett, J.L. (1989): Relationships between fear of humans, productivity and cage position of laying hens. British Poultry Science, 30: 505-518.

Hemsworth, P. H.; Coleman, G. J.; Barnett, J. L. and Jones, R. B. (1994): Behavioural responses to humans and the productivity of commercial broiler chickens. App. Anim. Behav. Sci., 41: 101-114.

Hocking, P. M.; Bernard, R. and Maxwell, M. H. (1999): Assessment of pain during locomotion and the welfare of adult male turkeys with destructive cartilage loss of the hip joint. Br. Poult. Sci., 40: 30-34.

Huber-Eicher, B. and Sebö, F. (2001): The prevalence of feather pecking and development in commercial flocks of laying hens. App. Anim. Behav. Sci., 74: 223-231.

Hughes, B.O. (1985): Feather loss as a problem: how does it occur? In: Proceedings, Third European Seminar on Poultry Welfare. Ed. Wegner, R.M. WPSA, Celle pp $177-$ 188.

Jones, R. B. (1985): Fearfulness of hens caged individually or in groups in different tiers of a battery and the effects of translocation between tiers. Br. Poult. Sci., 26: 399-408.

Jones, R. B. (1986): The tonic immobility reaction of the domestic fowl: A review. World's Poult. Sci. J., 42: 82-96.

Jones, R. B. (1989): Chronic stressors, tonic immobility and leucocytic responses in the domestic fowl. Physiol. Behav., 46: 439-442.

Jones, R. B. (1996): Fear and adaptability in poultry: insights, implications and imperatives. Wld Poult. Sci. J., 52: 131-174.

Jones, R. B., Beuving, G. and Blokhuis, H.J. (1988): Tonic immobility and heterophil/lymphocyte responses of the domestic fowl to corticosterone infusion. Physiol. Behav., 42: 249-253.

Jones, R.B. and Faure, J.M. (1981): Tonic immobility (righting time) in laying hens housed in cages and pens. App. Anim. Ethol., 7: 369-372.

Jones, R.B. and Hughes, B.O. (1986): Fearfulness and abnormalities in the chicken's egg shell - is there a link? In: Proceedings of the International Symposium on Applied Ethology in Farm Animals (Ed Czako, J), Hungarian Society of Agricultural Sciences, Budapest, pp. 171-175.

Kjaer, J. B. and Vestergaard, K. S. (1999): Development of feather pecking in relation to light intensity. App.Anim Behav. Sci., 62: 243-254.

Lane, R. (1987): Abnormal findings in avian haematology. Proceedings First International Conference on Zoological and Avian Medicine, Hawaii.

Mahboub, H. D. H. (2004): Feather pecking, body condition and outdoor use of two genotypes of laying hens housed in different free range systems. PhD Thesis, Leipzig University, Germany.

Mahboub, H. D. H.; Müller, J. and Von Borell, E. (2004): Outdoor use, tonic immobility, heterophil/lymphocyte ratio and feather condition in free- 
range laying hens of different genotype. Br. Poult. Sci., 45: 738-744.

Maxwell, M.H. (1993): Avian leucocyte responses to stress. Wld Poult. Sci. J., 49: 34-43.

McAdie, T. M. and Keeling, L. J. (2000): Effect of manipulating feathers of laying hens on the incidence of feather pecking and cannibalism. App. Anim. Behav. Sci., 68: 215-229.

McLean, K. A.; Baxter, M. R. and Michie, W. (1986): A comparison of the welfare of laying hens in battery cages and in a perchery. Res. Develop. Agri., 3: 93-98.

Nicol, C.J. (1987): Behavioural responses of laying hens follow a period of spatial restriction. Anim. Behave., 35: 1709-1719.

Okpokho, N. A; Craig, J. V. and Milliken, G .A. (1987):

Density and group size effects on caged hens of two genetic stocks differing in escape and avoidance behaviour. Poult. Sci., 66: 1905-1910.
SAS Institute Inc., (1999): STAT User's Guide, Version 8, Cary, NC, USA

Scott, G. B.; Barbara, J. C. and Nicola, R. L. (1998): The fear levels after transport of hens from cages and a freerange system. Poult. Sci., 77: 62-66.

Shen, P. and Patterson, L. T. (1983): A simplified Wright's stain technique for routine avian blood smear staining. Poult. Sci., 62: 923-924.

Tauson, R.; Elwinger, K. and Ambrosen, T. (1984): Evaluation of procedures for scoring the integument of laying hens - independent scoring of plumage condition. Acta Agriculturae Scandinavica, 34, 400-408.

Veslergaard, K. (1982): The significance of dust bathing for the wellbeing of the domestic hen. Tierhaltung, 13: 109118.

Wood-Gush, D. G. M. (1972): Strain differences in response to sub-optimal stimuli in the fowl. Anim. Behav., 20: 72-76.

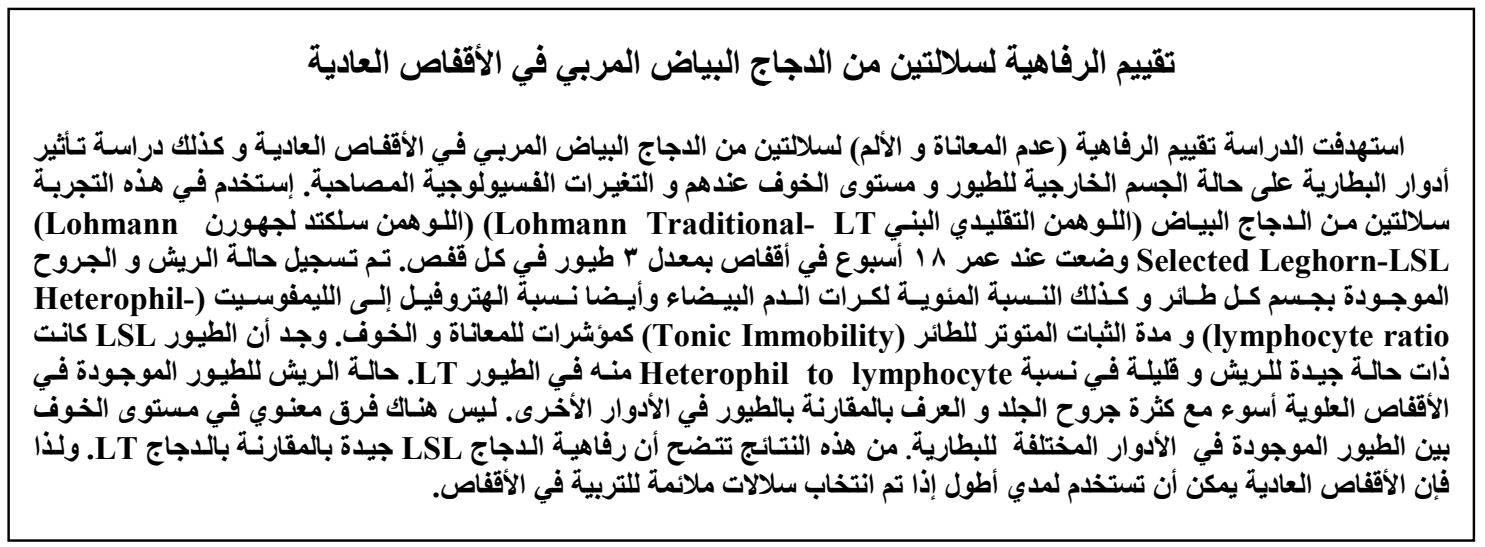


